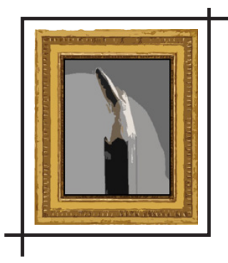

\title{
JUVENTUDE(S) NEGRA ENCARCERADA: A OFICIALIZAÇÃO DO CÁRCERE OU VITTIMAS DE UM SISTEMA EXCLUDENTE?
}

\author{
Marlene Almeida de Ataíde*
}

Resumo: Este artigo tem como objetivo realizar uma reflexão crítica à luz de autores que discutem sobre a temática da juventude, na perspectiva de levantar os fatores que levam ao encarceramento os jovens, principalmente aqueles que pertencem à raça negra, residentes quase majoritariamente nas periferias urbanas, local onde as políticas sociais públicas costumam atuar de costas para esses sujeitos. Na atualidade, são alarmantes os dados disponiveis pelos institutos de pesquisas no que diz respeito ao aumento do índice de jovens encarcerados no sistema prisional brasileiro. Esse sistema excludente não propicia o retorno desses jovens à sociedade para que possam levar uma vida com dignidade.

Palavras-chave: Juventude(s). Criminalização da pobreza. Sistema carcerário. Preconceito. Estigma.

\section{PARA INÍCIO DE CONVERSA...}

Há, no nosso país, um processo de seletividade e triagem perverso, imposto principalmente àqueles jovens negros oriundos de segmentos sociais pobres, que mal conseguem adentrar nos insumos sociais e, quando o fazem, é de forma precária e com pouquíssimas possibilidades de romper com o ciclo de pobreza a que estão submetidos.

Apesar de estarmos no século XXI, grande parte da nossa juventude pertence ainda a um universo reduzido e espesso, no qual sobram os riscos de todo tipo e faltam as oportunidades mais básicas. Suas vidas se degradam em termos pessoais e sociais, resultado da violência exacerbada que só poderá ser combatida ou reduzida a partir de mecanismos que não sejam somente repressivos, mas que sejam educativos e permitam solucionar as vulnerabilidades a que os jovens estão expostos. Não obstante alguns avanços, o Brasil não possui uma forma concreta de organização que contemple o atendimento às necessidades da juventude negra, principalmente aquela inserida nas camadas sociais pobres.

\footnotetext{
* Mestra e doutora em Serviço Social pela Pontifícia Universidade Católica de São Paulo (PUC-SP). Docente do curso de Graduação em Medicina, da pós-graduação em Residência Multiprofissional e da pós-graduação Psicologia Social da Universidade Santo Amaro (Unisa). Líder de grupo de pesquisa credenciada pelo CNPO. Linha de Pesquisa centrada na área das Ciências Sociais Aplicadas. E-mail: maataide@yahoo.com.br
} 
Embora o Estatuto da Juventude seja inovador nos seus múltiplos aspectos, está distante de um cumprimento integral, porque ainda nos deparamos com estratos de jovens que são os mais vulneráveis a algumas das maiores ameaças aos direitos - exploração sexual, uso e abuso de drogas, exploração do trabalho, violência etc. Ainda, a escola como instituição socializadora, muitas vezes e por diferentes motivos, exclui esses jovens, o que também acontece com as incertezas do mercado de trabalho que os remete a uma instabilidade profissional com a falta da oferta de serviços acessíveis à cultura, ao esporte e ao lazer. Todas essas situações apontam para práticas de exclusão e de limitação das oportunidades cujas consequências geralmente são a delinquência, a prostituição, o uso de drogas, o envolvimento com atividades ilícitas e especialmente, mas não exclusivamente, o narcotráfico, com forte impacto sobre a segurança e a saúde, a mortalidade e a morbidade dos jovens.

Portanto, as situações constatadas indicam que as demandas por políticas públicas para a juventude permanecem como estado de coisas, precariamente resolvidos no âmbito de políticas destinadas a um público mais amplo - com o qual os jovens têm que competir pelo espaço de atendimento - sem chegar a se apresentar especificamente como problemas políticos (RUA, 1998, p. 739).

Nessa direção, o jovem negro é aquele que está mais vulnerável e mais afetado pela ausência de políticas públicas que atendam às suas reais necessidades. Dessa forma, embora não seja uma plausivel justificativa, resta-Ihe, em algumas vezes, somente trilhar caminhos tortuosos e sem retorno, quando, então, a única política que o acolhe, todavia de forma perversa e precária, é a da Segurança Pública por meio do encarceramento.

\section{DE QUAL JUVENTUDE ESTAMOS FALANDO?}

Neste artigo, a ênfase da discussão está voltada para a(s) juventude(s) negra(s), pobre(s) e periférica(s), ou seja, aquelas que engrossam a cada dia o sistema carcerário brasileiro, criminalizadas pela vulnerabilidade em que (sobre)vivem.

Os jovens de subúrbios em ascensão econômica demandam acesso à cidadania econômica e social. Diante da incapacidade de atendimento as suas necessidades, os mesmos são tratados pelo viés policial e penal e criminalizados em suas ações, principalmente, pela perspectiva baseada na noção (verdadeira-falsa) de "violências urbanas", que é um non-sense sociológico e estatístico, e que guia, entretanto, a retórica e a ação do governo atual (WACQUANT, 1999).

De acordo com Peralva (2007, p. 18, grifo nosso):

Não por acaso, parte considerável da sociologia da juventude constituir-se-á então como uma sociologia do desvio: jovem é aquilo ou aquele que se integra mal, que resiste à ação socializadora, que se desvia em relação a certo padrão normativo. 
Conforme Abramo (2007, p. 73),

Quando os jovens são assunto dos cadernos destinados aos "adultos", no noticiário, em matérias analíticas e editoriais, os temas mais comuns são aqueles relacionados aos "problemas sociais", como violência, crime, exploração sexual, drogadição, ou as medidas para dirimir ou combater tais problemas.

Ainda persiste na sociedade a forte imagem dos jovens que assustam e ameaçam a integridade social. Na verdade, esses jovens são frutos ou, na melhor das hipóteses, vítimas de um processo de exclusão profunda que marca nossa sociedade e, ao mesmo tempo, aprofunda as tendências do individualismo pela busca exagerada do prazer e, para tanto, apresentam comportamentos de forma desregrada e amoral. Isso acontece porque se aprofunda ainda mais a fratura do esgarçamento social que os vitima (ABRAM0, 2007).

Podem tornar-se, assim, junto com o medo, objeto da nossa compaixão e de esforços para denunciar a lógica que os constrói como vítimas e de ações para salvá-los dessa situação. Mas dificilmente como sujeitos capazes de qualquer tipo de ação propositiva, como interlocutores para decifrar conjuntamente, mesmo que conflituosamente, o significado das tendências sociais do nosso presente e das saídas e soluções para elas (ABRAM0, 2007, p. 89).

\section{JUVENTUDE(S): ALGUMAS DEFINIÇÕES}

Geralmente, parte-se da ideia de que a juventude é, ao mesmo tempo, uma condição e uma representação social. De um lado, há um caráter universal posto pelas transformações do individuo numa determinada faixa etária. De outro, há diferentes construções históricas e sociais relacionadas a esse tempo ou ciclo da vida.

Assim, a construção social da juventude pode ocorrer de forma muito variada nas diferentes sociedades e em diferentes momentos históricos, pois cada sociedade e cada grupo social lida e representa de maneira diversa com esse momento.

Portanto, construir uma aproximação conceitual do que é juventude não parece uma tarefa fácil, já que o conceito não se restringe a uma categoria sociológica, constituindo um processo sociocultural demarcado pela preparação dos individuos para assumirem o papel de adulto na sociedade, nos planos familiar e profissional, principalmente porque os critérios que a compõem são históricos e culturais.

Peralva (2007, p. 18) ressalta, com propriedade, que

[...] a juventude é, ao mesmo tempo, uma condição social e um tipo de representação. Se há um caráter universal dado pelas transformações do individuo numa determinada faixa 
etária, na qual completa o seu desenvolvimento físico e enfrenta mudanças psicológicas, é muito variada a forma como cada sociedade, em um tempo histórico determinado e, no seu interior, cada grupo social vai lidar e representar esse momento. Essa diversidade se concretiza nas condições sociais (classes sociais), culturais (etnias, identidades religiosas, valores), de gênero e também das regiões geográficas, dentre outros aspectos.

Assim, lograr uma compreensão sobre a juventude significa analisá-la e contextualizá-la dos pontos de vista histórico e sociocultural, pois os aspectos econômicos, as transformações sociodemográficas, a classe social e as características daqueles que são jovens no campo, nas cidades, bem como as interações sociais, não podem ser dissociadas dos fenômenos característicos da sociedade em geral (ARCE, 1999).

Groppo (2000, p. 7-8) caracteriza a juventude como "categoria social", de modo que é vista como uma "concepção, representação ou criação simbólica", fabricada pelos grupos sociais ou pelos próprios individuos tidos como jovens, "para significar uma série de comportamentos e atitudes a ela atribuidos". A juventude, como camada social, não apenas passou por várias modificações ao longo do tempo, como também é uma representação e uma situação social simbolizada e vivida com muitas diferenças na realidade diária, devido à sua combinação com outras situações sociais, tais como as diferenças culturais, nacionais e de localidade, além das distinções de etnia e gênero.

Sposito e Carrano (2003) e Dayrell (2005), por exemplo, trabalham a noção de juventude numa visão pautada pela diversidade e utilizam o termo no plural, "juventudes". Tal diversidade concretiza-se nas condições sociais (classes sociais), culturais (etnias, identidades religiosas, valores), de gênero, nas regiões geográficas, entre outros aspectos. É muito diferente, por exemplo, a noção do que é o jovem, de como vivencia essa fase e de como é tratado em famílias de classe média ou de camadas populares, em um grande centro urbano ou no meio rural. Portanto, não se pode inserir a juventude em critérios rígidos, como uma etapa com um início e um fim predeterminados, muito menos como um momento de preparação que será superado quando entrar na vida adulta.

Segundo Groppo (2000, p. 9), a concepção de juventude fundamenta-se "em dois critérios" que, apesar de se inter-relacionarem, nunca se harmonizam totalmente: "o critério etário e o critério sócio-cultural". 0 primeiro sempre presente. 0 segundo demonstra que o jovem e seu comportamento modificam-se de acordo com a classe social, o grupo étnico, a nacionalidade, o gênero, os contextos nacionais e regionais; ainda cabe apontar que o critério tempo é fundamental para entender tais modificações. Nota-se que a intenção é demonstrar que a categoria social juventude, da mesma forma que outras categorias sociais embasadas nas faixas etárias, apresenta uma importância fundamental para a compreensão de inúmeras características das sociedades contemporâneas, bem como do seu modo de funcionamento e de suas transformações. 
Foracchi (1977, p. 302-303, grifo nosso), uma das pioneiras no Brasil que buscaram uma definição para a juventude, na sua obra clássica intitulada 0 estudante e a transformação da sociedade brasileira, realiza uma análise sobre essa categoria, ainda pertinente na contemporaneidade, sobretudo, quando ressalta o seguinte:

\begin{abstract}
A juventude é, ao mesmo tempo, uma fase da vida, uma força social renovadora e um estilo de existência. Se a concebermos como a etapa que antecede a maturidade e que apresenta caracteristicas singulares, notaremos que ela corresponde a um momento definitivo da descoberta da vida e da história e a uma fase dramática da revelação do eu. Sob esse segundo aspecto, é uma experiência particular que se universaliza como componente indispensável da formação da pessoa, como afirmação dos seus recursos e das suas potencialidades humanas. Os quadros dessa experiência particular e os caminhos da sua universalização são, no entanto, socialmente estabelecidos. Isto quer dizer que cada sociedade constitui o jovem à sua própria imagem. As representações que valoriza e as manipulações que estimula tendem, no geral, a fazê-lo agir dentro dos limites que ela mesma estabelece e que são os limites da sua preservação [...]. Menos do que uma etapa cronológica da vida, menos do que uma potencialidade rebelde e inconformada, a juventude sintetiza uma forma possivel de pronunciar-se diante do processo histórico e de constituí-lo, engajando-se.
\end{abstract}

Groppo (2000) tem situado a juventude como uma fase intermediária entre a infância e a idade adulta. No entanto, para Levi e Schmitt (1996, p. 14), o termo juventude, ao longo da história, ganha outros sentidos, quais sejam:

De um contexto a outro, de uma época a outra, os jovens desenvolvem outras funções e logram seu estatuto definidor de fontes diferentes: da cidade ou do campo, do castelo feudal ou da fábrica do século XIX. [...] Tampouco se pode imaginar que a condição juvenil permaneça a mesma em sociedades caracterizadas por modelos demográficos totalmente diferentes.

Nessa direção, considerar a juventude entre períodos da vida humana pressupõe concebê- la entre limites máximos e mínimos, dependendo dos critérios estabelecidos em cada momento histórico (ABREU, 2003). Assim, como uma construção histórica, cultural e socialmente, a juventude deve ser compreendida além dos marcos etários e biológicos, sendo indissociável dos contextos sociocultural, político e econômico.

Para Carrano (1999), a maneira mais simples de uma sociedade conceituar o que é um jovem é estabelecer critérios para situá-lo numa determinada faixa de idade, na qual se circunscreve o grupo social da juventude. De fato, esse princípio é utilizado na realização de estudos estatísticos, na definição de idade de escolarização obrigatória, na formulação de 
políticas de compensação social, na atribuição de idades mínimas para o início do trabalho profissional, na idade mínima para a responsabilidade penal, na classificação de programas de televisão etc. As idades não possuem um caráter universal. A própria noção de infância, juventude e vida adulta é resultante da história e varia segundo as formações humanas.

Zaluar (1997, p. 25) esclarece que "o foco na idade, no período atribulado da adolescência e no desenvolvimento de uma subcultura (ou subculturas) da juventude, resulta na tentativa de explicar pela fase da vida as práticas de diferentes origens e diversas posições na sociedade".

Portanto, os motivos que submetem os jovens ao sistema carcerário pressupõem igualmente a compreensão de que o desenvolvimento não ocorre isolado, mas integrado, pois ele vivencia ativamente as ações sociais, políticas, econômicas e culturais de sua conjuntura social, notadamente aqueles aspectos mais relacionados ao seu segmento de classe.

\section{O SISTEMA CARCERÁRIO BRASILEIRO: ALGUMAS CONSIDERAÇÕES}

"A urgência no Brasil, como na maioria dos paises do planeta, é lutar em todas as direções não contra os criminosos, mas contra a pobreza e a desigualdade"

(WACQUANT, 2001, p. 12).

Prisões e hospícios se encaixam perfeitamente no conceito de instituição total, proposto por Goffman (1996, p. 11), a saber:

Uma instituição total pode ser definida como um local de residência e trabalho, onde um grande número de indivíduos com situação semelhante, separados da sociedade mais ampla por considerável período de tempo, leva uma vida fechada e formalmente administrada.

Gofmann (1996) considera como instituições totais aquelas que se caracterizam pelo seu fechamento intramuros e funcionam na modalidade de internação, compostas por um grupo de sujeitos submetidos à privação de liberdade que ocupam os espaços em tempo integral. Nesse espaço, os sujeitos habitam como se estivessem nos seus locais de residência, nos quais realizam as atividades da vida diária e possuem todo o aparato para outras atividades, como trabalho, lazer e espaço de alguma atividade específica, correcional, educativa etc.

Goffman (1996, p. 16-17, grifos nossos) procurou dividir as instituições totais em cinco grupos, ao ressaltar o seguinte:

Em primeiro lugar, instituições criadas para cuidar das pessoas que, segundo se pensa, são incapazes e inofensivas; nesse caso estão as casas para cegos, velhos, órfãos e indigentes. 
Em segundo lugar, há locais estabelecidos para cuidar de pessoas consideradas incapazes de cuidar de si mesmas e que são também uma ameaça à comunidade, embora de maneira não intencional; sanatórios para tuberculosos, hospitais para doentes mentais e leprosários. Um terceiro tipo de instituição total é organizado para proteger a comunidade contra perigos intencionais, e o bem-estar das pessoas assim isoladas não constitui o problema imediato: cadeias, penitenciárias, campos de prisioneiros de guerra, campos de concentração. Em quarto lugar, há instituições estabelecidas com a intenção de realizar de modo mais adequado alguma tarefa de trabalho, e que se justificam apenas através de tais fundamentos instrumentais: quartéis, navios, escolas internas, campos de trabalho, colônias e grandes mansões (do ponto de vista dos que vivem nas moradias dos empregados). Finalmente, há os estabelecimentos destinados a servir de refúgio do mundo, embora muitas vezes sirvam também como locais de instrução para os religiosos; entre exemplos de tais instituições, é possivel citar abadias, mosteiros, conventos e outros claustros.

Na cultura brasileira, um dos traços que merecem uma demarcação diz respeito à cultura instalada ao longo da história no sistema carcerário, cultura que vem se reproduzindo nas instituições denominadas "totais" (aquelas que segregam o sujeito quando ele não se coaduna às normas em vigor da sociedade em que vive). Dessa forma, o sistema carcerário brasileiro na contemporaneidade é uma instituição totalitária que se encontra numa situação caótica e, na realidade, não fornece elementos para a (res)socialização dos seus usuários.
A penalização serve aqui como uma técnica para a invisibilização dos "problemas" sociais que o Estado, enquanto alavanca burocrática da vontade coletiva, não pode ou não se preocupa mais em tratar de forma profunda, e a prisão serve de lata de lixo judiciária em que são lançados os dejetos humanos da sociedade de mercado (WACQUANT, 2007, p. 21, grifo do autor).

$\mathrm{Na}$ literatura que analisa as políticas penais nos últimos 25 anos e em particular as questões prisionais, encontramos em Loïc Wacquant (2001) e Zygmunt Bauman (1999) que constataram que o encarceramento em massa presente nesse período é uma decorrência da nova percepção de que os riscos devem ser reduzidos, as políticas de prevenção ao crime devem ser mais amplas e os criminosos devem ser mais severamente punidos e controlados.

Na sua consagrada obra denominada As prisões da miséria, o sociólogo francês Loïc Wacquant (2001, p. 7, grifo do autor) transmite uma nota aos leitores brasileiros ao intitular de forma interrogativa "Rumo a uma ditadura sobre os pobres?" e ressalta:

A penalidade neoliberal apresenta o seguinte paradoxo: pretende remediar com um "mais

Estado policial e penitenciário" o "menos Estado" econômico e social que é a própria causa 
da escalada generalizada da insegurança objetiva e subjetiva em todos os paises, tanto do Primeiro como do Segundo Mundo. [...] a penalidade neoliberal ainda é mais sedutora e mais funesta quando aplicada em paises ao mesmo tempo atingidos por fortes desigualdades de condições e de oportunidades de vida e desprovidos de tradição democrática e de instituições capazes de amortecer os choques causados pela mutação do trabalho e do indivíduo no limiar do novo século.

Ainda de acordo com Wacquant (2001, p. 8): "a sociedade brasileira continua caracterizada pelas disparidades sociais vertiginosas e pela pobreza de massa que, ao se combinarem, alimentam o crescimento inexorável da violência criminal, transformada em principal flagelo das grandes cidades". De forma contundente, o autor enfatiza o seguinte:

Desenvolver o Estado penal para responder às desordens suscitadas pela desregulamentação da economia, pela dessocialização do trabalho assalariado e pela pauperização relativa e absoluta de amplos contingentes do proletariado urbano, aumentando os meios, a amplitude e a intensidade da intervenção do aparelho policial e judiciário, equivale a (r)estabelecer uma verdadeira ditadura sobre os pobres (WACQUANT, 2001, p. 10, grifo do autor).

Assim, a construção de novas cadeias e o aprimoramento dos códigos trazem benefícios políticos, sobretudo as mais visiveis, conforme Bauman (1999, p. 127) "a espetaculosidade versatilidade, severidade e disposição - das operações punitivas importa mais que a sua eficácia". Ou seja, importa mais que a quantidade de crimes detectados e reportados que servem para "ocupar a atenção do público com os perigos dos crimes e da criminalidade" (BAUMAN, 1999, p. 128).

A construção de novas prisões, a redação de novos estatutos que multiplicam as infrações puniveis com prisão e o aumento das penas - todas essas medidas aumentam a popularidade dos governos, dando-Ihes a imagem de severos, capazes, decididos e, acima de tudo, a de que "fazem algo" não são apenas explicitamente pela segurança individual dos governados, mas, por extensão, também pela garantia e certeza deles - e fazê-lo de uma forma dramática, palpável, visivel e tão convincente (BAUMAN, 1999, p. 127).

De acordo com Wacquant (2001), o sistema penitenciário brasileiro é uma das "piores jaulas do Terceiro Mundo", porém elevada a "uma escala digna do Primeiro Mundo", ao considerar as suas dimensões, a indiferença estudada pelos políticos e o público-alvo. 0 autor enumera uma série de questões que vão desde os estarrecedores entupimentos nesses estabelecimentos até a ausência de higiene, "a falta de espaço, ar, luz e alimentos" (WACOUANT, 2001, p. 110). 
Desse modo, torna-se evidente, com base na análise de Wacquant (2001), que o sistema carcerário, além de não cumprir o seu papel de agente ressocializador, é também um lócus que fere a dignidade humana, além de atuar na contramão dos direitos humanos. Para Bauman (1999, p. 122):

\begin{abstract}
Nenhuma evidência de espécie alguma foi encontrada até agora para apoiar e muito menos provar as suposições de que as prisões desempenham os papéis a elas atribuídos em teoria e de que alcançam qualquer sucesso se tentam desempenhá-los - enquanto a justiça das medidas mais especificas que essas teorias propõem ou implicam não passa nos testes mais simples de adequação e profundidade ética.
\end{abstract}

Em sua obra Vigiar e punir: nascimento da prisão, Foucault (1987, p. 165-166) atribui ao filósofo e jurista inglês Jeremy Bentham a proposta de construção do Panóptico, descrita pelo autor da seguinte forma:

\begin{abstract}
[...] na periferia uma construção em anel; no centro, uma torre; esta é vazada de largas janelas que se abrem sobre a face interna do anel; a construção periférica é dividida em celas, cada uma atravessando toda a espessura da construção; elas têm duas janelas, uma para o interior, correspondendo às janelas da torre; outra, que dá para o exterior, permite que a luz atravesse a cela de lado a lado. Basta então colocar um vigia na torre central, e em cada cela trancar um louco, um doente, um condenado, um operário ou um escolar. Pelo efeito da contraluz, pode-se perceber da torre, recortando-se exatamente sobre a claridade, as pequenas silhuetas cativas nas celas da periferia. Tantas jaulas, tantos pequenos teatros, em que cada ator está sozinho, perfeitamente individualizado e constantemente visivel.
\end{abstract}

0 modelo arquitetônico descrito por Foucault (1987) pode também ser implantado em outras instituições, sejam elas abertas ou fechadas, como escolas, hospícios, hospitais, indústrias, agências bancárias, entre outros, visto que não serve somente para vigiar os que nele se encontram como usuários e internos, mas também facilita a observação do funcionamento e da ordem geral da instituição, incluindo-se aí funcionários e visitantes.

\footnotetext{
O Panóptico [...] permite aperfeiçoar o exercício do poder. E isto de várias maneiras: porque pode reduzir o número dos que o exercem, ao mesmo tempo em que multiplica o número daqueles sobre os quais é exercido. [...] Sua força é nunca intervir, é se exercer espontaneamente e sem ruido (FOUCAULT, 1987, p. 170).
}

É nesse sistema prisional tão bem descrito por Foucault (1987) que vive, em nosso país, uma boa parte de presidiários, especialmente os mais jovens. Permanecem grande parte 
do tempo na mais completa ociosidade, excluídos de atividades que possam permitir um processo de (re)integração. Muitos desses jovens sequer tiveram a oportunidade de serem integrados nos bens e serviços produzidos socialmente. Esse é um lócus em que prevalece a ausência ou a insuficiência de programas que possam aproximá-los de algum projeto que seja realmente eficiente e que os contemple na sua plenitude.

As penitenciárias, como comumente denominadas, acabam por se tornar "fábricas de delinquentes" porque, na realidade, produzem a marginalização em vez de destruí-la, na medida em que separam, classificam e afastam o sujeito da sociedade mais ampla.

Ou ainda nos dizeres de Goffman (1996, p. 66):

Toda instituição total pode ser vista como uma espécie de mar morto, em que aparecem pequenas ilhas de atividades vivas e atraentes. Essas atividades podem ajudar os individuos a suportar a tensão psicológica usualmente criada pelos ataques do eu. [...] precisamente na insuficiência de tais atividades, podemos encontrar um importante efeito de privação das instituições totais.

Para alguns sujeitos da sociedade civil, as ameaças de fracasso no cumprimento de papéis sociais oportunizam mecanismos que facilitam o esconderijo em locais que fornecem maior segurança, mantendo as suas fantasias comercializadas por intermédio do cigarro, da bebida, cinema, TV, leituras, entre outros. Ao contrário das instituições totais, "tais materiais podem não estar ao seu alcance" (GOFFMAN, 1996, p. 66).

Outro ponto a ser ressaltado é que na sua consagrada obra Vigiar e punir Foucault (1987) já analisava os assuntos que hoje são centrais e recorrentes na discussão sobre o sistema carcerário, como a corrupção da polícia, os abusos de poder, o ócio, as más condições de vida do preso e de sua família, as reivindicações e revoltas dos detentos.

Foucault (1987, p. 28) assim resume a sua brilhante análise:

Palavra por palavra, de um século a outro, as mesmas proposições fundamentais se repetem. E são dadas a cada vez como a formulação enfim obtida, enfim aceita de uma reforma até então sempre fracassada. Poder-se-ia ter tomado as mesmas frases ou quase as mesmas de outros periodos "fecundos" da reforma: o fim do século XIX, e o "movimento da defesa social"; ou ainda os anos mais recentes, com as revoltas dos detentos.

Entretanto, há em nosso país as mais variadas visões de homem e mundo que refletem sobre o sistema carcerário, tema que ocupa os noticiários, além de teses, dissertações e artigos científicos. 0 sistema carcerário vincula-se ao debate sobre a questão da segurança nos estados, e quanto maior a escalada da violência, maior o debate sobre o seu papel social e político na recuperação ou na marginalização dos individuos no seu interior. 
Ou, conforme Wacquant (2001, p. 10), socializa-se entre os diversos paises em diferentes continentes, internacionalizando-se paralelamente à ideologia econômica neoliberal da qual é a tradução em matéria de "justiça", uma globalização de "políticas e técnicas agressivas de segurança made in USA", importando-se como soluções mágicas para o crucial problema da violência criminal. Para o autor, na América Latina, por exemplo, o tratamento policial e judiciário da miséria é essencialmente antagônico à consolidação de uma sociedade democrática, uma vez que isso significaria (r)estabelecer uma verdadeira ditadura sobre os pobres. Ou ainda, "A sociedade brasileira continua caracterizada pelas disparidades sociais vertiginosas e pela pobreza de massa que, ao se combinarem, alimentam o crescimento inexorável da violência criminal, transformada em principal flagelo das grandes cidades" (WACQUANT, 2001, p. 10).

Verifica-se ainda o quão os poderes constituídos insistem em reformas dos sistemas carcerários, resultando sempre em projetos fracassados, que não contribuem para a diminuição do crime, mas que se transformam em escolas da criminalidade, iniciando presos que não cometeram crimes graves na carreira da delinquência, da crueldade. 0 sistema carcerário brasileiro vem passando por uma crise sem precedentes na história do país. São incontáveis as rebeliões, as fugas e os motins que nele ocorrem. Geralmente são atos perpetrados por aqueles que estão encarcerados, sem que haja, de fato, mecanismos eficientes do poder público para evitar essas ocorrências. Segundo Wacquant (2007, p. 126-127), "o encarceramento serve, antes de tudo, para regular, se não perpetuar a pobreza e para armazenar os dejetos humanos do mercado". Ou na melhor das hipóteses: "Volta-se para aqueles que compõem o subproletariado negro das grandes cidades, as frações desqualificadas da classe operária, aos que recusam o trabalho mal remunerado e se voltam para a economia informal da rua, cujo carro-chefe é o tráfico de drogas" (WACQUANT, 1999).

\footnotetext{
0 comércio de entorpecentes é uma das atividades econômicas mais complexas e lucrativas do mundo capitalista atual. É uma "empresa" concentradora de renda, altamente lucrativa, que explora mão de obra barata e, portanto, totalmente adaptada ao mundo neoliberal. Outra característica curiosa é a forte alienação do trabalho que produz: seus "funcionários" não possuem a menor ideia do montante do lucro da empresa. Esta mão de obra é formada por jovens, cada vez mais jovens, arruinados afetivamente, esvaziados de reconhecimento e visibilidade e sem qualquer perspectiva de um futuro breve (FREIXO, 2018, p. 1).
}

Wacquant (1999) traz a questão dos jovens negros de um bairro nos Estados Unidos que foi objeto da sua pesquisa e já haviam passado pela detenção. No entanto, essa mesma premissa vem ocorrendo no Brasil, pois o tráfico de drogas vem cooptando os jovens de bairros periféricos para a venda de drogas. A pesquisa realizada em 2012 pela revista Fórum revelou que os motivos que levam esses milhares de pessoas para trás das grades são quase sempre os mesmos: "tráfico de drogas (125 mil presos)" (PITTS, 2012). 


\section{CRIMINALIZAÇÃO DA POBREZA: PRECONCEITOS E ESTIGMAS ATRIBUÍDOS AOS JOVENS NEGROS, POBRES E PERIFÉRICOS}

"Se eu pudesse eu dava um toque em meu destino/Não seria um peregrino nesse imenso mundo cão/Nem o bom menino que vendeu limão/Trabalhou na feira pra comprar seu pão/Não aprendia as maldades que essa vida tem/Mataria a minha fome sem ter que roubar ninguém/Juro que nem conhecia a famosa Funabem/Onde foi a minha morada desde os tempos de neném/É ruim acordar de madrugada pra vender bala no trem/Se eu pudesse eu tocava em meu destino/Hoje eu seria alguém/Seria eu um intelectual/Mas como não tive chance de ter estudado em colégio legal/ Muitos me chamam pivete/Mas poucos me deram um apoio moral/Se eu pudesse eu não seria um problema social/Se eu pudesse eu não seria um problema social"

(Seu Jorge, "Problema social").

A violência que assola o nosso país não escolhe lugares nem pessoas a quem atingir. No entanto, aqueles que residem em bairros periféricos são os mais vulneráveis a esse fenômeno, pois as periferias, geralmente povoadas por bairros em que persiste a insuficiência de estrutura básica, não podem ser comparadas com os bairros nobres que são providos de maior segurança, embora não estejam os seus moradores isentos da violência.

Todavia, esses lugares nobres diferem dos bairros populares onde a segurança praticamente inexiste e, quando ocorre, é na perspectiva da criminalização dos pobres ao atingir quase que majoritariamente aqueles que são negros e vítimas contumazes da violência que assola o país. Segundo Faustino (2015, p. 125), fica evidente "que a população negra (e os jovens negros em especial) tem sido, desde o período posterior à abolição, vítima sistemática de um violento processo de diferenciação radicalizada".

Embora não seja considerado um fato novo, no cenário contemporâneo, a insegurança no Brasil tem a particularidade de não ser atenuada, mas nitidamente agravada pela intervenção das forças da ordem. 0 uso rotineiro da violência letal pela polícia militar e o recurso habitual da tortura por parte da polícia civil principalmente para fazer os suspeitos "confessarem", as execuções sumárias e os "desaparecimentos" inexplicados geram um clima de terror entre as classes populares que são seu alvo e banalizam a brutalidade no seio do Estado. Esse contexto pode ser interpretado como

[...] o recorte da hierarquia de classes e da estratificação etnorracial e a discriminação baseada na cor, endêmica nas burocracias policial e judiciária. Sabe-se, por exemplo, que em São Paulo, como nas outras grandes cidades, os indiciados de cor "se beneficiam" de uma vigilância particular por parte da polícia, têm mais dificuldade de acesso a ajuda jurídica e, por um crime igual, são punidos com penas mais pesadas que seus comparsas brancos (WACQUANT, 2001, p. 9). 
De acordo com Zaccone (2015, p. 118), "criam-se condutas de racismo que não vão resolver o problema. Por exemplo, quais as condutas previstas no crime de racismo. 0 processo de criminalização é um só e ele vai ser sempre seletivo". Além de seletivo, àqueles que são criminalizados por algum ato que fere os preceitos postos pela sociedade são atribuídos os preconceitos. De acordo com o Dicionário Houaiss da Língua Portuguesa (HOUAISS; VILLAR, 2001, p. 2282), preconceito significa "qualquer opinião ou sentimento, quer favorável ou desfavorável, concebido sem exame crítico". Segundo Albuquerque Júnior (2007, p. 10), "O preconceito, como a própria palavra deixa entrever, é um conceito prévio, um conceito sobre algo ou alguém que se estabelece antes que qualquer relação de conhecimento ou de análise se estabeleça".

Desse modo, o preconceito pode emitir uma opinião precipitada que inviabiliza qualquer esforço na tentativa de conhecer o outro, o diferente, em sua diferença e na sua alteridade. Além do preconceito, outra categoria presente é o estigma, ou seja, os rótulos que esses sujeitos carregam pela vida inteira como um atributo da sua identidade ao serem denominados de ladrão, assassino, criminoso, prostituta, traficante, vagabundo, somente para citar alguns adjetivos.

Sobre a questão do estigma, Goffman (1988, p. 12) frisa "que é a situação do indivíduo que está inabilitado para a aceitação social plena", porém "A sociedade estabelece os meios de categorizar as pessoas e o total de atributos considerados como comuns e naturais para os membros de cada uma dessas categorias".

A categoria estigmatização é analisada por Goffman (1988, p. 46) da seguinte forma:

\begin{abstract}
[...] a estigmatização do indivíduo está associada com a sua admissão a uma instituição de custódia, como uma prisão, um sanatório ou um orfanato, a maior parte do que ele aprende sobre o seu estigma ser-Ihe-à transmitida durante o prolongado contato intimo com aqueles que irão transformar-se em seus companheiros de infortúnios.
\end{abstract}

Goffman (1988) enfatiza a exclusão social plena: o indivíduo é visto como incapaz para aceitação social, caracterizada pelo estigma, no caso dos jovens negros e periféricos, principalmente por pertenceram à classe social pobre. Dessa forma, o estigma pode ser considerado como uma relação que se estabelece entre atributo e estereótipo.

\footnotetext{
Cada vez que alguma pessoa que tem um estigma particular alcança notoriedade, seja por infringir a lei, ganhar um prêmio ou ser o primeiro em sua categoria, pode-se tornar o principal motivo de tagarelice de uma comunidade local, esses acontecimentos podem até mesmo ser notícia nos meios de comunicação da sociedade mais ampla (GOFFMAN, 1988, p. 37).
}

Assim, o estigma torna o sujeito indesejável pelas pessoas de outros ambientes sociais, bem como por seu próprio meio. Mesmo que pertença a um determinado grupo, se o sujeito 
não apresentar atributos importantes ou algum atributo diferente dos demais sujeitos, será visto e tratado de forma desigual. Portanto, o estigma torna-se uma marca social que pode vir a julgar o outro, de forma tal que incorre numa exclusão que submete esses individuos à invisibilidade.

No caso deste nosso personagem, a invisibilidade decorre principalmente do preconceito ou da indiferença. Uma das formas mais eficientes de tornar alguém invisível é projetar sobre ele ou ela um estigma, um preconceito. Quando o fazemos, anulamos a pessoa e só vemos o reflexo de nossa própria intolerância. Tudo aquilo que distingue a pessoa, tornando-a um individuo; tudo o que nela é singular desaparece (SOARES, 2005 p. 165).

De acordo com o Atlas da violência de 2017:

Mais de 318 mil jovens foram assassinados no Brasil entre 2005 e 2015. Em 2015 foram 31.264 homicídios de jovens entre 15 e 29 anos, uma redução de 3,3\% na taxa em relação a 2014. De cada 100 pessoas que sofrem homicidio no Brasil, 71 são negras. Jovens e negros do sexo masculino continuam sendo assassinados todos os anos como se vivessem em situação de guerra. [...] Os negros com idade entre 12 e 29 anos apresentavam mais risco de exposição à violência que os brancos na mesma faixa etária (CERQUEIRA et al., 2017, p. 27-32).

Enquanto não se envidarem esforços por intermédio dos órgãos competentes, a sociedade continuará reproduzindo o medo, clamando pela diminuição da idade penal e principalmente pelo encarceramento em massa, que, além de não solucionar a questão social que se manifesta na vida desses jovens, significa manter o sistema carcerário da forma em que está posto, em detrimento de uma educação que seja transformadora. Se esse cenário for mantido, teremos, sim, nessa direção, um encarceramento sem precedentes no nosso país.

\section{CONSIDERAÇÕES FINAIS}

Diante de todo o exposto no presente artigo, considera-se importante indagar: 0 sistema carcerário brasileiro foi implantado para propiciar de fato a (res)socialização dos egressos à sociedade ou apenas para excluí-los ainda mais, pois a prisão se consolida como uma forma de domesticar corpos, encontrando no discurso da (res)socialização apenas a sua base ideológica?

Assim se configura e se legitima, com base na ideia do trabalho, uma espécie de violência criada pela sociedade moderna. Como parte do sistema repressivo penal, serve como instrumento de controle social, formulando aparatos destinados à punição e à domesticação, 
reproduzindo a violência da própria sociedade, oficializando e estigmatizando as categorias sociais excluidas.

Dentre os problemas mais agravantes, pode-se mencionar a superlotação nos presídios como uma questão histórica aquém de ser superada apenas com a construção de novas prisões que operam como medidas paliativas e não geram qualquer forma de suprir os sujeitos com ferramentas (res)socializantes. Todas as medidas são pautadas em ações pontuais/ focalizadas que não abrangem os que se encontram privados da liberdade como um todo. Trata-se de ações que permitem tão somente um determinado marketing como forma de prestar um serviço à sociedade, já que é quem sustenta a grande massa de encarcerados. Entretanto, pode-se verificar que a própria arquitetura do sistema prisional já fala por si só. São prisões que apresentam um projeto arquitetônico sombrio e subumano, que sequestra subjetividades, fere sobremaneira os direitos humanos e, por não cumprir a sua função precípua, conserva a reprodução das suas origens e, além de tudo, desumaniza o humano.

No Brasil estamos vivendo um verdadeiro genocídio que abate sobremaneira jovens pobres, negros e residentes nas periferias. No entanto, além da intolerância depositada nesses jovens, é bastante evidente o quão se tornam alvos dos preconceitos e do estigma, seja na condição de vítima ou de perpetradores de atitudes delituosas. Por serem negros e pobres e não possuírem alternativas para se empoderar dos espaços da cidade, são empurrados para as periferias dos centros urbanas, que são consideradas como "o lugar do outro", pois denunciam o paradoxo do lugar ocupado por aqueles que não usufruem de espaços urbanos mais centrais e fazem das periferias das cidades seus locais de moradia.

Não obstante, as denúncias encaminhadas aos órgãos nacionais e internacionais bem como demais agências de direitos apontam os resultados danosos para a vida desses jovens, ou seja, a prática contumaz do estigma e o genocídio que vitimam jovens negros pobres, restando-Ihes apenas como espaço de sociabilidade a exclusão pela via do encarceramento.

0 sistema carcerário reflete a imagem da sociedade que produz e reproduz a lógica das suas contradições, as quais, não por acaso, se desdobram na falta de uma política afirmativa para o referido sistema. Há uma crucial ineficiência na forma da gestão empreendida ao longo da sua existência, produzindo tão somente a exclusão daqueles que estão vivenciando esse lócus precário e perverso, ou seja, um encarceramento em massa, que não seleciona nem recupera e que se volta para a população negra e pobre, tendo em vista que a sociedade brasileira tem na sua marca a exclusão social pela discriminação racial e também pelas desigualdades sociais que atingem espetacularmente aqueles que se encontram em desvantagem social, ou seja, as minorias que estão submetidas às populações majoritárias ou dominantes. 


\title{
Black youth(s) imprisoned: the officialisation of the prison or victims of excluding system?
}

\begin{abstract}
This article aims to carry out a critical reflection in the light of authors discussing the theme of youth in the perspective of raising the factors that lead to the incarceration of young people, especially those who belong to the race predominantly in the urban peripheries, where public social policies tend to act on their backs to these people. At present, the data available by the research institutes regarding the increase in the number of young prisoners in the Brazilian prison system are alarming, this system exclusionary, since it does not allow these young people to return to society and lead a life with dignity.
\end{abstract}

Keywords: Youth(s). Poverty criminalization. Prision system. Preconception. Stigma.

\section{REFERÊNCIAS}

ABRAMO, H. W. Considerações sobre a tematização social da juventude no Brasil. In: FÁVERO, 0. et al. Juventude e contemporaneidade. Brasília: Ministério da Educação, 2007. p. 73-90.

ABREU, A. A. de. Quando eles eram jovens revolucionários. In: VIANNA, H. (Org.). Galeras cariocas: territórios de conflitos e encontros culturais. 2. ed. Rio de Janeiro: UFRJ, 2003

ALBUQUERQUE JÚNIOR, D. M. de. Preconceito contra a origem geográfica e de lugar: as fronteiras da discórdia. São Paulo: Cortez, 2007. (Preconceitos, v. 3).

ARCE, J. M. V. Vida de barro duro: cultura popular juvenil e grafite. Rio de Janeiro: UFRJ, 1999.

BAUMAN, Z. Globalização: as conseqüências humanas. Tradução Marcus Penchel. Rio de Janeiro: Zahar, 1999.

CARRANO, P. C. R. Angra de tantos reis: práticas educativas e jovens tra(n)çados da cidade. 1999. Tese (Doutorado em Educação) - Universidade Federal Fluminense, Niterói, Rio de Janeiro, 1999.

CERQUEIRA, D. et al. Atlas da violência 2017. Rio de Janeiro: Ipea, FBSP, 2017.

DAYRELL, J. A música entra em cena: o rap e o funk na socialização da juventude. Belo Horizonte: UFMG, 2005.

FAUSTINO, D. M. A dignidade esfolada no asfalto: "nós (os "cidadãos de bem") e "eles" (os "outros" na agenda da violência militarizada). In: SILVA, G. M. da (Org.). Desmilitarização da polícia e da política: uma resposta que virá das ruas. Uberlândia: Puebla, 2015.

FORACCHI, M. M. O estudante e a transformação da sociedade brasileira. São Paulo: Companhia Editora Nacional, 1977. 
FOUCAULT, M. Vigiar e punir: nascimento da prisão. Petrópolis: Vozes, 1987.

FREIXO, M. Prisões, crime organizado e exército de esfarrapados. Disponível em: <https:// www2.mppa.mp.br/sistemas/gcsubsites/upload/60/Pris\%C3\%83\%C2\%B5es,\%20crime\%20 organizado\%20e\%20ex\%C3\%83\%C2\%A9rcito\%20de\%20esfarrapados.pdf>. Acesso em: 3 fev. 2018.

GOFFMAN, E. Estigma: notas sobre a manipulação da identidade deteriorada. Tradução Márcia Bandeira de Mello Leite Nunes. Rio de Janeiro: LTC, 1988.

GOFFMAN, E. Manicômios, prisões e conventos. 5. ed. São Paulo: Perspectiva, 1996.

GROPPO, L. A. Juventude: ensaios sobre a sociologia e história das juventudes modernas. Rio de Janeiro: Difel, 2000.

HOUAISS, A.; VILLAR, M. S. Dicionário Houaiss da língua portuguesa. Rio de Janeiro: Objetiva, 2001.

LEVI, G.; SCHMITT, J. C. (Orgs.). A história dos jovens: a época contemporânea. Tradução Cláudio Marcondes, Nilson Moulin. São Paulo: Companhia das Letras, 1996. v. 2.

PERALVA, A. T. 0 jovem como modelo cultural. Revista Brasileira de Educação, São Paulo, v. 5-6, p. 15-24, 2007.

PITTS, N. País revela, em números, realidade carcerária do pais. 2012. Disponível em: <https:// www.revistaforum.com.br/pesquisa-revela-em-numeros-realidade-carceraria-do-pais/>. Acesso em: 16 ago. 2015.

RUA, M. das G. As políticas públicas e a juventude dos anos 90. In: CNDP. Jovens acontecendo na trilha das politicas públicas. Brasilia: CNPD, 1998. p. 731-752. 2 v.

SOARES, L. E. Cabeça de porco. Rio de Janeiro: Objetiva, 2005.

SPOSITO, M. P.; CARRANO, P. C. Juventude e políticas públicas no Brasil. Revista Brasileira de Educação, São Paulo, v. 24, p. 16-39, 2003.

WACQUANT, L. A criminalização da pobreza. Tradução Suely Gomes Costa. Mais Humana, dez. 1999. Disponivel em: <https://anidabar.wordpress.com/2013/04/26/criminalizacao-dapobreza/>. Acesso em: 14 set. 2018.

WACQUANT, L. As prisões da miséria. Tradução André Telles. Rio de Janeiro: Jorge Zahar Editor, 2001.

WACQUANT, L. Punir os pobres: a nova gestão da miséria nos Estados Unidos [a onda punitiva]. Tradução Sérgio Lamarão. Rio de Janeiro: Revan, 2007. 
ZALUAR, A. Gangues, galeras e quadrilhas: globalização, juventude e violência. In: VIANNA, H. Galeras cariocas: territórios de conflitos e encontros culturais. Rio de Janeiro: UFRJ, 1997. ZACCONE, O. A (des) construção do criminoso. In: SILVA, G. M. da (Org.). A desmilitarização da polícia e da política: uma resposta que virá das ruas. Uberlândia: Pueblo, 2015. p. 116-117.

Recebido em fevereiro de 2018. Aprovado em abril de 2018. 